\title{
The Porja: A Study on Pediatric Practices
}

\author{
S. Narahari*, M. Narasinga Rao, S. Bhaskara Babu and A. Aparna \\ Department of Anthropology, Andhra University, Visakhapatnam 530 003, \\ Andhra Pradesh, India \\ *Fax:0891-2844232, *E-mail: narahari_samudrala@yahoo.co.in
}

KEYWORDS Pediatric Health. Breast-feeding. Primitive Tribe. Andhra Pradesh

\begin{abstract}
Pediatric Health in terms of Feeding Practices were recorded on 260 ever married women, who have atleast a child in their reproductive span, belonging to the Porja, a Primitive Tribal Group of Visakhapatnam District, Andhra Pradesh. The sample hails from 18 villages of Munchangiputtu and Pedabayalu Mandals. The results show that almost all the mothers started breast feeding to their new born immediately. About 71 percent of the respondents squeezed out the 'colostrum' (milk) ere to start the feeding the baby, thereby depriving of their babies from 'colostrum', a thick yellow liquid rich in factors that provide natural immunity. This may be due to illiteracy and lack of awareness about the nutritive and immunity value of the colostrum.. The duration of lactation was noticed mostly for 2 years ( 42 percent) followed by 3years (38 percent) and 4years (17 percent). Very few mothers ( 3 percent) lactate their babies below the age of 1year due to conditions of ill health. The practice of supplementary feeding starts from 6 months onwards which is greater during 8-12 months (60 percent).The predominant type of supplementary feeding is 'Ambali' a liquid form of rice or chodi ( 87 percent) and a few of them are fed with rice in mashed solid form. The results are discussed in the light of available information on other local tribes besides focusing the relevance of illiteracy, status of awareness etc., on Pediatric health care practices.
\end{abstract}

\section{INTRODUCTION}

Healthy children are the real wealth of any community. Pediatric health care practices have become vital issue for the $3^{\text {rd }}$ world countries where high foetal and child mortality were reported. Many studies (Ghosi 1989; Sinha and Pandey 1998) revealed that mother's milk is the easiest to digest to the baby than any other substance. Even in many communities, where sweet water or honey is given, it is meant only for the purification of the child. The first feeding for any child is the mother's milk. Breast-feeding has its socioeconomic, psychological, biological and immunological aspects (Neetimakanti 1991). Human milk is known to be an ideal, safe and complete food for infants and being available at a suitable temperature. It helps to promote normal dental and facial development. .

Tribals are a neglected lot and discriminated in terms of income distribution and social status. Most of them are desperately poor, backward, generally uneducated and lead a hard and miserable life (Thakur et al. 1991). In India, there are more than 400 tribal communities of which 75 are recognized as Primitive Tribal Groups (PTG) by the government in 1989 and the total Primitive Tribal population of the country is $24,12,666$ as per 1991 census which constitutes 3.56 percent of total Scheduled tribes (Dash Sharma, 2006). Though there are reports on health and nutritional aspects of some Primitive Tribal Groups (see Dash Sharma 2006), no study exists on child health care practices from the Visaka agency area. Therefore, an endeavour is made, for the first time, to report the Pediatric health care practices such as breast feeding, and supplement feeding during weaning period among a primitive tribal group viz., the Porja of Visakhapatnam District, Andhra Pradesh.

\section{The People}

The Porja is a small hill tribe with a population size of 16,479 (Census, 1991) mainly distributed near the hill slopes of Munchangiputtu, Ananthagiri and Pedabayalu mandals of Visakhapatnam District of Andhra Pradesh. They are migrants from Orissa state for about 300 years back to the present habitat. They are said to be a section of Khond/Gadaba of Ganjam (Thurston,1975). There are 7 endogamous units who differ in language, food habits, customs and traditions. They are Barendi Jhodia (beaf eaters and speak Oriya), Pengo Poraja (buffaloe eaters and speak Oriya), Khondi or Kindi Poraja (a section of Khond who eat beef and buffalo but speak Khond), Parangi Poraja (a section of Gadaba 
who may or may not eat buffalo, but speak Gadaba dialect), Bonda or Nanga Poraja (a section of the Gadaba and speak Gadaba dialect), Tagara Poraja (a section of Koya and sepeak Koya or Telugu), and Dur Poraja or Didayi Poraja (who speak Oriya). However, there exists no marital links yet they have commensal relations and claim of higher social status by some units. They speak Parji akin to Bhatri, a form of Oriya (Grierson 1906). The Porja living in Andhra Pradesh belong to the Parengi Porja (Kumar and Narahari 1987, Sachi Devi and Naidu 2003) on whom the present study has been conducted.

\section{MATERIAL AND METHODS}

Data pertaining to breast feeding practices, duration of lactation, supplementary feeding were collected from 260 ever-married women (aged 18+ years) who have atleast a child, belonging to Porja, a Primitive Tribal Group of Andhra Pradesh. The sample is drawn from a total of 18 villages including 16 villages from Munchangiputtu and 2 villages from Pedabayalu Mandals of Visakhapatnam District. The purposive sampling method was adopted. Field work was conducted during January-March, 2006. An Interview based on structured questionnaire method was employed during the data collection.

\section{RESULTS AND DISCUSSION}

Tribal women in India are at a great disadvantage due to illiteracy and ignorance. Various research studies on tribal population of India revealed that their diets are nutritionally deficient (Kupputhai and Mallika 1993) Most of the studies proved that the first milk i.e. the colostrum is good for the healthy growing of a newborn (Khan 1990; Ghosh 1993; Deka 2004). But, the tribals treat it as impure and not easily digested to the newborn. So they throw it away and give sugar water or Amudam (Castor Oil) or honey to the children, which cleans the baby's digestive system. The pre-lactation liquid was given with the help of cotton or small piece of cloth soaked, in the solution. It was reported that the tribals of Gujarat (Tavkar 1983), Rajasthan (Gupta and Singh 1985) and lrulas of Nilgiris (Maurya 1987) put the new borns to breast for their first feed within 24 hours to 96 hours after birth. This phenomenon is clearly reported (Table 1) in the present study as 71 percent of women said that they have initiated the breast milk to their new born babies immediately after delivery (i.e., after 2-4 hours) but squeezed out, before initiation, the first milk that contain colostrum, which is nutritious and immunity provider in the new borns. Only 29 percent of the mothers, who are generally educated by the local ANM, fed their new born with first breast milk containing colostrums. A similar finding was noted for the Gadaba tribe of Vizianagaram District (Hemalatha, 2005) and the Savaras of Srikakulam District (Narahari et al. 2006) where 72 percent and 80 percent of the lactating mothers, respectively practice the squeezing out of the first breast milk. In contrast, Nanibabu et al. (2006) observed that among the Koyadora tribe of East Godavari District, Andhra Pradesh, only 20 percent of the lactating mothers squeezed out the first breast milk before initiation. Thus, the Primitive Tribal groups, the Porja, the Gadaba and the Savara deprive colostrums to their new borns due to not only high illiteracy but also blind beliefs and customs towards colostrum even today.

The Supplementary feeding and duration of lactation are interdependent. Further, there is an inverse relationship between the two i.e., as breast feeding or lactation period increases it delays the start of supplementary feeding. Among the Porjas, an average lactation period is found to be 2 years ( 41.50 percent) followed by 3 years ( 37.69 percent) and 4 years (17.31 percent), which shows a comparatively longer period of lactation (Table1). Because of the prolonged period of lactation, the supplementary feeding is delayed by $8-12$ months ( 60.39 percent) to above 1 year ( 23.46 percent) in this tribal population. Moreover, the Porjas believe that the supplementary feeding should be started then only when the child is supposed to walk. Regarding the type of supplementary feeding, most of the respondents ( 88.46 percent) said that they fed liquid in the form of 'ambali' or gruel or mashed rice liquid to their children (Table 1)

\section{CONCLUSION}

Therefore, due to high illiteracy level, deep routed customs, beliefs and practices, the Porja children seem to be deprived of colostrum during infancy, improper supply of nutrients during weaning period also hampers on their growth and development. Further, the WHO (2001) rec- 
Table 1: Pediatric care components (Percentage) among the Porjas

\begin{tabular}{lr}
\hline Pediatric care component & Percentage \\
\hline Squeezing-out Milk (Colostrum) & 71.15 \\
(a) Yes & 28.85 \\
(b) No & \\
Duration of Lactation (in Years) & 03.46 \\
(a) One & 41.54 \\
(b) Two & 37.69 \\
(c) Three & 17.31 \\
(d) Four & 00.00 \\
Beginning of Supplementary Feeding (in Months) \\
(a) Less than 6 \\
(b) 6-8 & 16.15 \\
(c) 8-12 & 60.39 \\
(d) Above 12 & 23.46 \\
Type of Supplementary Feeding & 88.46 \\
(a) Liquid & 11.54 \\
(b) Solid &
\end{tabular}

ommendation of practice of breast feeding at least for 6 months as an appropriate period for normal growth, free from gastro-intestinal infections and prolonged post-partum amennorhea though exceeds the said specified period in the present population, yet the unhygienic conditions prevailed during breast feeding as well weaning periods, and malnutrition of the mothers during pre- and post-natal periods affect pediatric health status are also to be considered which demands intervention programs, to monitor infant growth and improve maternal nutritional status among the Porjas.

\section{ACKNOWLEDGEMENTS}

The author (SNH) is highly grateful to the University Grants Commission, New Delhi for the financial support under the Major Research Project scheme (vide letter no. F.5-173/2004(HRP) dated 21-10-2004). Thanks are due to ITDA, Paderu and the tribal people for their cooperation and help during the data collection.

\section{REFERENCES}

Census of India 1991. Special Tables for Scheduled Tribes. Series 2. Andhra Pradesh. Part IX (iii). S.S. Jaya Rao. Delhi: Controller of Publications.

Dash Sharma P 2006. Anthropology of Primitive Tribes in India. New Delhi: Serial Publications (2006).

Deka 2005. Infant and young child feeding practices of three tribal communities in Assam. Proceedings of $48^{\text {th }}$ All India Annual Conference of Indian Public Health Association, Bhubaneswar (2004) cited from Hemalatha.

Ghosh S 1993. Infant Feeding, Food and Nutrition. New Delhi: Department of Women and Child Development, Ministry of Human Research Development, Government of India.

Ghosh S 1989. You and Your Child. New Delhi: Voluntary Health Association of India.

Grierson GA 1906. Linguistic Survey of India. Vol. IV. Munda and Dravidian Languages. Government of India. Superintendent. Calcutta: Government Press.

Gupta KD, Singh RN 1985. A study of child rearing practices under 6 years of age in one of the tribal area of Rajasthan (Pendwara block of Sirohi District). Abstract. Jodhpur: Dept. of Pediatrics.

Hemalatha M 2005. Breast-Feeding Practices among Gadabas. M.Sc. Dissertation (Unpublished), Visakhapatnam: Andhra University.

Khan ME 1990. Breast Feeding and Weaning Practices in India. Asia-Pacific Population Journal, 5(1): 71-87.

Kupputhai U, Mallika N 1993. Nutrional Status of Adult Women Belonging to Khond, Gadaba and Porja Tribes of Andhra Pradesh. Ind J Nutri \& Diet, 30(7): 173-179.

Kumar DMS, Narahari S 1987. The Parangi Porojas: A Morpho-genetic Study, SAP, 9: 1-5.

Maurya S 1987. Feeding and health care of children among Irula tribals. Ind J Home Sci, 17(2): 55-58.

Nanibabu P, Sri Virajarani J, Sambasiva Rao R, Hemalatha M 2006. Effect of breast - feeding on the health status of children and their mothers. $A b$ stract. National Workshop on Health Problems and Health Care Systems among the tribes of India. Visakhapatnam: Andhra University, P.44.

Narahari S, Narasinga Rao M, Bhaskar Babu S, Aparna A 2006. Breast Feeding Practices among the Savaras. Abstract. National Workshop on Health Problems and Health Care Systems among the tribes of India. Visakhapatnam: Andhra University, P.45.

Neetimakanti 1991. Care and development of children in tribal areas.ICCW News Bulletin, 39: 39-44.

Sinha Arti , Pandey Hema 1998. Maternal and Infant Feeding Practices of 'Ho' Tribe Women in Bihar. Ind J Nutri \& Diet, 35(12): 325-328.

Sachi Devi S, Naidu JM 2003. Paroja/ Parja/ Porja. In: People of India. New Delhi: East West Press Private Limited, Vol. XIII, Part 2, pp. 1403-1408.

Thurston E 1975. Castes and Tribes of Southern India VI: 207-222. Madras: Government Press.

Tavkar N 1983. Child Care amongst the Tribals of Panchmahals. Report of ECCE, pp. 13-15.

Thakur DS, Thakur DC, Saini AS 1993. Socio-economic impact of tribal development programmes in Himachal Pradesh .J Rural Develop, 10: 823-830.

World Health Organization (WHO) 2001. The Optimal Duration of Exclusive Breast-Feeding Results of WHO Systemic Review. Geneva: WHO. 